\title{
Isolation of compounds from Sargassum wightii by GCMS and the molecular docking against anti-inflammatory marker COX2
}

\author{
P. Balachandran, V.Parthasarathy *, T.V. Ajay Kumar \\ Immunology Laboratory, Department of Pharmacy, Annamalai University, Chidambaram, India \\ Corresponding author email: vapartha@yahoo.com
}

\begin{abstract}
Keywords: Sargassum wightii, COX2 inhibitor, protein data bank, GC-MS, QikProp, molecular docking and ADME properties, anti-inflammatory agents
\end{abstract}

\begin{abstract}
The study focused on the molecular docking of GC-MS isolated compounds from the Sargassum wightii against inflammatory marker Cycloxigenase-2 (COX2). Seven compounds isolated by GC-MS were tested for their anti-inflammatory action using insilico analysis. The crystal structure obtained from the protein data bank was docked against seven compounds and the glide score as well as glide energy were determined using Schrödinger Maestro software (version 2013.1). The results of molecular docking showed that out of the seven bioactive compounds tested, methyl salicylate, benzoic acid, 2-hydroxy-,ethyl ester, diethyl phthalate, hexadecanoic acid, ethyl ester and (E) -9-octadecenoic acid ethyl ester were effectively inhibited the COX2 protein. The ADME properties of the compounds analyzed using Qikprop version 3.6 software of Schrodinger suite and the results showed that all the compounds were biologically active and the scores were within the acceptable range. This study revealed that the possibility of using these compounds against COX2 to treat inflammation.
\end{abstract}

\section{INTRODUCTION}

Inflammation is the tissue reaction against infectious agents like microbes, irritants or any other foreign substances. It is a part of the host defense mechanisms that is known to be involved in the inflammatory reactions associated with the release of histamine, bradykinin and prostaglandins. Clinically inflammation, reported by Cornelius Celsus of Rome 2000 years ago, is rubor (redness) or calor (heat) and /or dolar (pain) at the affected region [1] because of a complex biological response of vascular tissues to harmful stimuli including pathogens, irritants or damaged cells [2].

Cyclooxygenases (COX) or prostaglandin endoperoxide synthases (PGHS) are the key enzymes in the synthesis of prostaglandins, the main mediators of inflammation, pain and increased body temperature (hyperpyrexia). In human two main isoforms of COX proteins, namely Cyclooxygenases -1 (COX1) and Cyclooxygenases-2 (COX2) [3] are found. The COX1 is responsible for formation of important biological mediators like prostanoids which includes prostaglandins, prostacyclin and thromboxane and is involved in protecting the stomach, whereas COX2 is involved in the inflammation associate with pain as well as it plays a major role in prostaglandin biosynthesis by inflammatory cells and central nervous system. Many NSAIDs inhibit both COX1 and COX2 enzymes and reduces inflammation, damaging the lining of the stomach leading to gastric problems like stomach upset, ulceration and blood bleeding from the stomach and intestine. Antagonizing specific COX2 enzyme is an attractive therapeutic target to develop potent anti-inflammatory drugs [4].

Although several natural products have been shown to modulate COX2 expression but the results are not clear whether these drugs directly interact with the gene product or modulate transcription factors. Computational chemistry offers the possibility to explore these interactions through protein-ligand docking procedures. Docking methods are valuable tools for drug development and most current approaches assume a rigid receptor structure to allow docking of large numbers of possible ligands and putative binding sites on a receptor molecule [5]. 
The aggregates of small plants, animals and organisms that float or drift in great numbers in saline water are the important ocean's food chain. Among the boundaries of the marine, there are much bigger organism is called as seaweeds. Seaweeds are the collection of algae that will occupy the sea or back water and have the capability of absorbing sunlight to synthesis the carbohydrate using water and carbon dioxide [6]. In the marine ecosystem seaweeds are one of the natural resources for the foods, feed and bioactive compounds such as drugs and diagnostic agents. Until now more than 2,400 natural marine products are being identified from the different seaweeds of subtropical and tropical countries and are used as food, fodder, fertilizer and medicine [7, 8, and 9]. Sea weeds are used as an ingredient in the food preparations of Korean, Japanese and Chinese. Antiviral, antifungal, antibacterial, anti-oxidant, anti-inflammatory, hypercholesterolemia and hypolipidemic and antineoplastic [10] agents are the important bioactive agents isolated from the sea weeds. The Europeans and Americans also use sea weeds as additives in food preparations [11]. Currently the usage of sea weeds in the form of salads and soups are becoming common among Asians since they are low-calorie foods [12].

The marine algae "Sargassum wigitti" found abundantly in shorelines of many parts of Asia. In India it is widely distributed in the southern coasts of Tamilnadu. Sargassum wigitti possess sulphated polysaccharides, which is responsible for mosquito repellent and larva control activity. The alginic acid from Sargassum wightii has been explored for possible anti-inflammatory effects [13].

In the present study the authors made a deputed attempt to predict the compounds of Sargassum wightii using GCMS analysis and generated the three-dimensional (3D) structure of COX2 from protein data bank. The model validated with standard parameters. Docking methodologies were used to test the binding ability of predicted compounds of Sargassum wighti to COX2. Ligands known to bind with COX2 were submitted to docking protocol GLIDE module (Schrodinger 2013.1) to establish relationships between their biological activity and the predicted binding affinities. This study could play a pivotal role in further functional characterization of the compounds to treat inflammatory disorder.

\section{MATERIALS AND METHODS}

Collection and Authentication of Algae. The brown marine algae "Sargassum wightii" belongs to the family "Phaeophyceae" was collected from Bay of Bengal during August, 2014 at Mandabam, Rameswaram region of Tamilnadu, India by handpicking during low tide. The collected sample was identified and authenticated by Dr. K.Sivakumar, Associate Professor, Department of Botany, Annamalai University, Tamilnadu, India. Voucher specimen (No. $\mathrm{SW} / \mathrm{PB} / 15$ ) was prepared and preserved in the Department of Botany, Annamalai University for future reference.

Processing of Algae sample. The collected algae sample were thoroughly cleaned manually in the sea water so as to remove the sand particles, epiphytes, pebbles, shells, loosely attached microorganisms and animal waste. The seaweeds packed in plastic bags to prevent evaporation and brought to the laboratory. The algal sample washed further with plenty of tap water followed by distilled water twice to remove the attached salts. The water was drained off and dried by spread over the blotting paper followed by further drying under the shade for two days and then washing with sterile distilled water to remove the remaining salt on the surface of the algae. This is process avoid pumping of the solvent during the extraction process. The algal samples were shade dried at room temperature for a period of one week and powered using electrical mixture grinder to get the particles of 40 meshes. The powder sample was packed in air tight plastic bags and stored in refrigerator until use. 
Preparation of Extract. The bioactive principles of the Sargassum wightii was extracted from $300 \mathrm{gm}$ of the powder sample with $1000 \mathrm{ml}$ of ethanol using soxhlet apparatus for 24 hours at $60^{\circ} \mathrm{C}$. The extract was concentrated to a semisolid consistency by distillation. The residue of the extract was kept in a wide mouth beaker and kept in room temperature for $8 \mathrm{hrs}$ until the solvent was removed. The crude extract consisted of two layers namely, the upper oil like layer and the lower water soluble layer. The upper layer was separated from the lower layers using separating funnel. The upper layer was used for the present study and lower water soluble layer was discarded.

GC-MS Analysis. The GC-MS analysis of ethanolic extract of Sargassum wightii carried out using the GC Clarus 500 Perkin Elmer coupled with Elite-5MS (5\% Diphenyl / 95\% Dimethyl poly siloxane), $30 \times 0.25 \mathrm{~mm} \times 0.25 \mathrm{~m}$ df column. Helium was used as a carrier gas at flow rate of 1.0 $\mathrm{ml} / \mathrm{min}$, Split 10:1. The injector was operated at $250^{\circ} \mathrm{C}$ and the oven temperature was programmed at $200^{\circ} \mathrm{C}$ at the rate of $10^{\circ} \mathrm{C} / \mathrm{min}-N o$ hold and up to $280^{\circ} \mathrm{C}$ at the rate of $5^{\circ} \mathrm{C} / \mathrm{min}-9 \mathrm{~min}$ hold. The compounds were predicted based on the NIST libraries and comparison of their retention directory, version year 2015 [14].

\section{MOLECULAR DOCKING}

It is a technique by which two molecules fit together in a 3D work space and also as a solution in structural biology and computer-aided drug design [15]. In this study, the two dimensional structures were drawn by using Chemdraw [16], which is a chemical structure drawing program from Windows. For the molecular docking analysis, the Schrodinger aided drug design software [17] was used.

Preparation of ligand structure. The ligands are freely available and are able to download from the web databases like ZINC [18] and Pubchem [19, 20], and they provide the knowledge about their biological activities. The small ligand molecule if unable to download, then it can be sketched using tools like Chemdraw or Chemsketch. Here the biological active compounds obtained from the GC-MS analysis were used for the docking studies. The structures of methyl salicylate, benzoic acid, 2-hydroxy- ethyl ester, diethyl phthalate, phytol, hexadecanoic acid-, ethyl ester, nhexadecanoic acid and (E)-9-Octadecenoic acid ethyl ester were drawn using the Chemdraw software. The 2D structure of the compounds were drawn individually and saved in ".mol" format for the easy use.

The seven structures are imported into the project table by opening the project table and the 3D structure of ligand is prepared using the module LigPrep 2.6 (Maestro 9.4, Schrodinger 2013.1). To have sensible bond lengths and bond angles, it must have all hydrogen's (filled valences) to the ligands, all the ligand structures were converted into its 3D structure and were optimized by the default setting using "OPLS 2005" force field. Selected the option known as "Generate all combination" and click "run" for the job to complete [21]. The ligands were converted into its 3D structure using the LigPrep module of Schrodinger maestro was given in Figure.1 


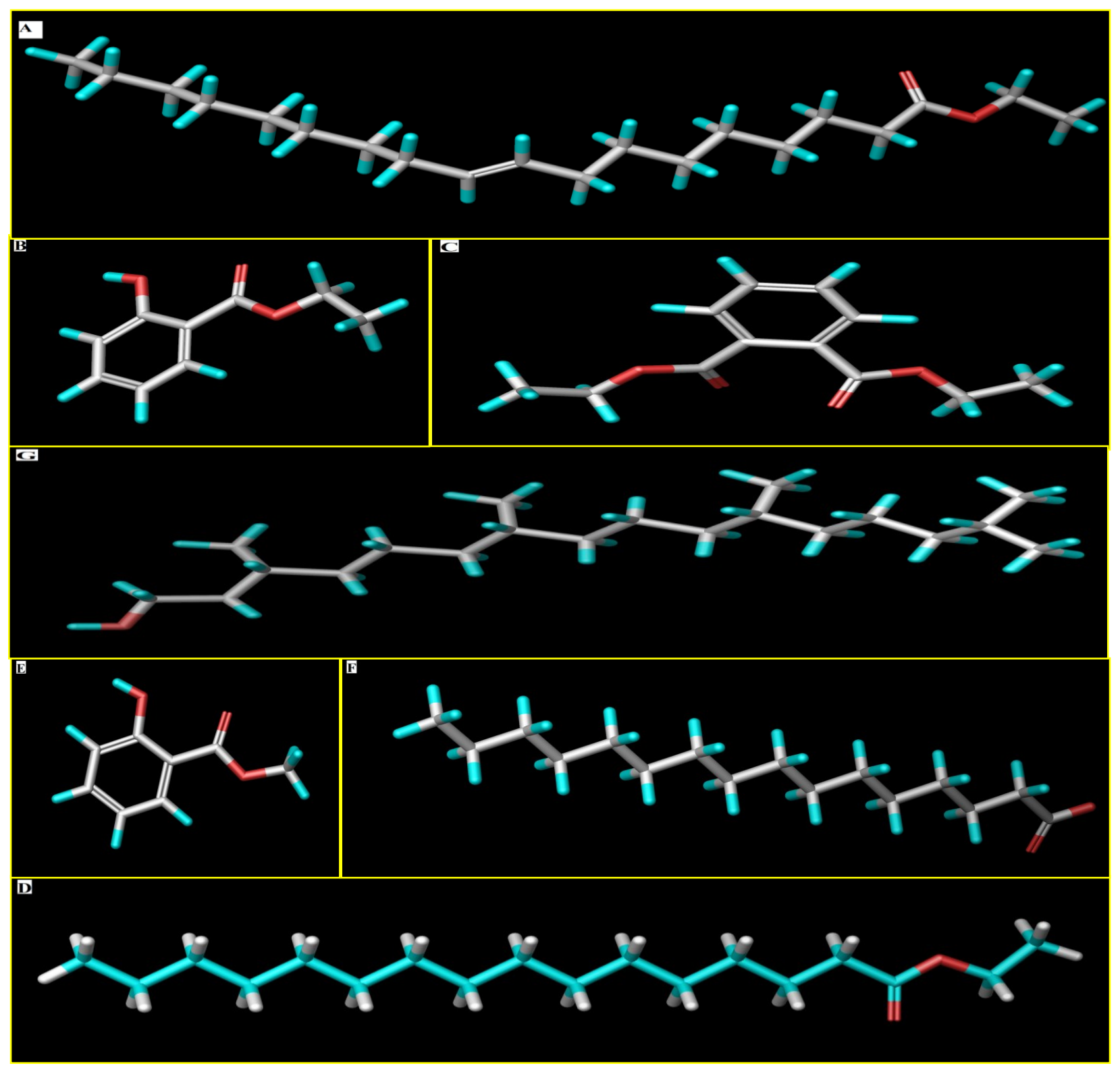

Figure.1. The structures of various ligands: (E)-9-Octadecenoic acid ethyl ester (A); Benzoic acid, 2-hydroxy- ethyl ester (B); Diethyl phthalate (C); Hexadecanoic acid (D); ethyl ester (E); Methyl salicylate (F); n-Hexadecanoic acid $(\mathbf{G})$ and Phytol $(\mathbf{H})$.

Protein Preparation. The protein data bank web is a collection of 3D structure of protein with more information about the experimentally established X-ray and NMR biomacromolecules and their complexes with or without ligands [22]. The crystal structure of the protein COX2 with a resolution of $2.40 \AA$ was downloaded from the www.PDB website (PDB entry 3LN1) and customized to be biologically active [23]. The protein may contain the heavy atoms, water molecules, cofactors, metal ions and can also be multimeric. So to achieve a biologically active protein, the raw 3D structure should be made to fit and available for docking study. This includes the removal of the water molecules from the cavity, stabilizing charges, generating the side chains and missing hydrogen atoms etc, according to the default limitation available on the module of "protein preparation wizard" (Schrodinger Maestro). Followed by this process the protein was processed to minimize the energy by using the kollman charges (OPLS 2005). Finally the receptor was made to biologically active and stable [24]. The grid was generated using the module "receptor grid generation". This will be performed if the prepared protein consists of ligand molecules. The ligand was identified by minimizing the protein and selecting the ligand. By using the grid generation the ligand was excluded and click "run" for the job to complete. 
Protein Ligand Docking. The prepared ligands using the "LigPrep" and the COX2 protein using the "protein preparation wizard" were docked using "Ligand docking" tool of Schrodinger maestro. The ligands were set to be flexible and the docking was manually set to the "extra (XP) precision mode". This will be usually the best choice (Grid based Ligand docking) for docking less numbers of ligands in "Ligand docking" module of Schrodinger Maestro (Glide 5.9). The interactions were calculated using the glide score, which was generated by the best fit of the ligand and the receptor. The ligands docked using GLIDE was graded according to their glide scoring function (most negative value). The function of scoring of the GLIDE docking program is shown in the G-Score or the docking score. The Glide score of each ligand is screened against the protein receptor COX2 protein [25]. The docking scores or the glide score (G-score) of the bioactive compounds were recorded and discussed.

ADME Properties Prediction. The compounds with highly negative glide scored against COX2 protein were selected for their ADME properties study using QikProp 3.6 module. QikProp helps in determining the pharmacokinetics and pharmacodynamics of the ligand by accessing the drug like properties. The predicted significant ADME (Absorption Distribution, Metabolism, Excretion) properties includes: Molecular weight (MW), H-Bond donor, H-Bond acceptor and $\log \mathrm{P}(\mathrm{O} / \mathrm{W})$ (QikProp 3.6, Schrodinger, 2012) [26].

\section{RESULTS AND DISCUSSION}

The chromatograms of the compounds from Sargassum wightii are shown in Figure.2 and the results of GC-MS analysis given in Table.1.

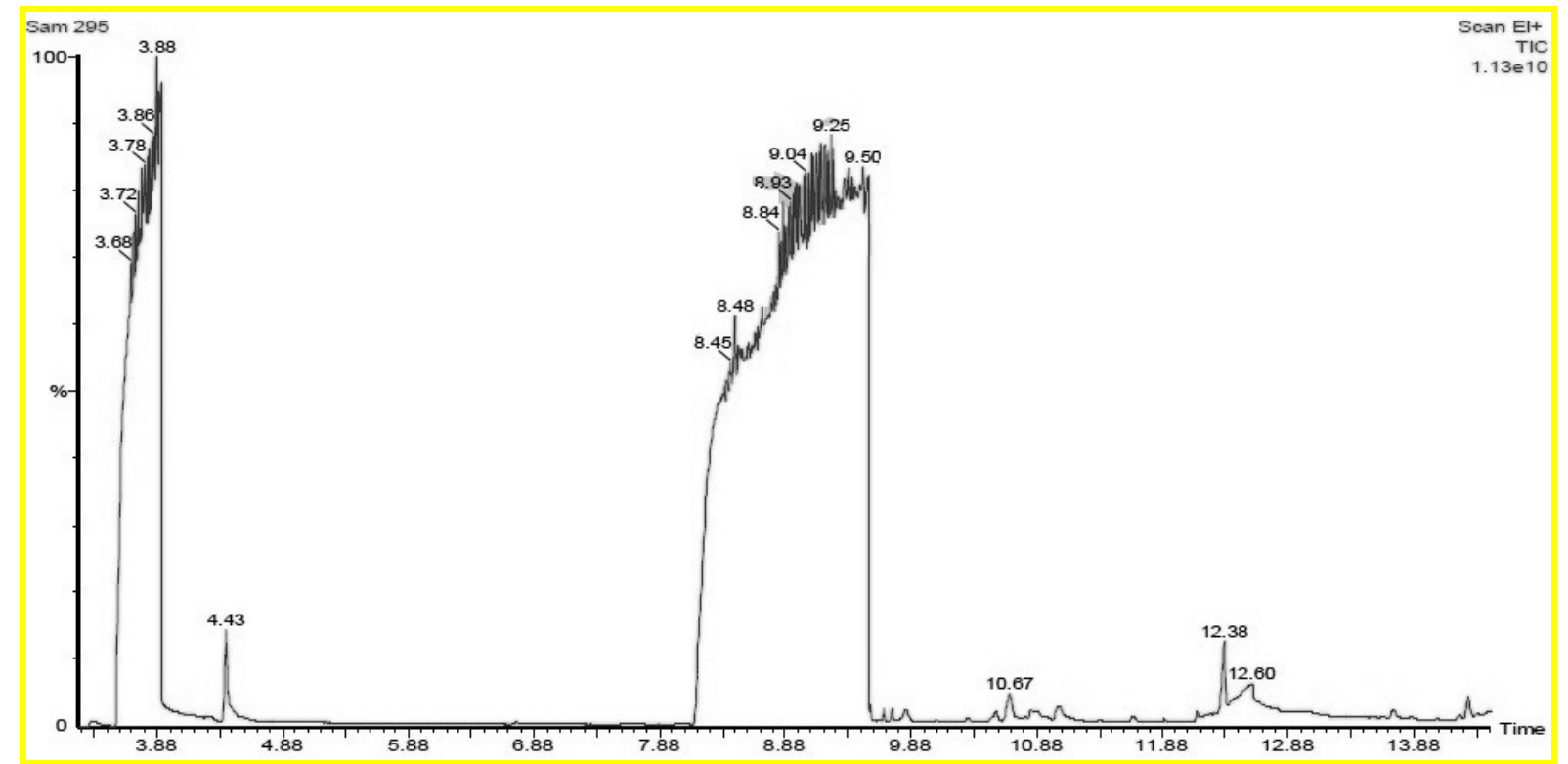

Figure.2. GC-MS peak level in the chromatogram graph of ethanolic extract of Sargassum Wightii

Table.1. The compounds with their molecular formula, amount [\%] determined from the chromatograph peak using NIST libraries and comparison of their retention time.

\begin{tabular}{|c|c|l|c|c|}
\hline Peak & RT & \multicolumn{1}{|c|}{ Name of the compound } & Molecular formula & Percentage [\%] \\
\hline 1 & 3.88 & Methyl Salicylate & $\mathrm{C}_{8} \mathrm{H}_{8} \mathrm{O}_{3}$ & 21.98 \\
\hline 2 & 4.43 & Benzoic acid, 2-hydroxy-, ethyl ester & $\mathrm{C}_{9} \mathrm{H}_{10} \mathrm{O}_{3}$ & 0.47 \\
\hline 3 & 9.25 & Diethyl Phthalate & $\mathrm{C}_{12} \mathrm{H}_{14} \mathrm{O}_{4}$ & 75.59 \\
\hline 4 & 10.67 & Phytol & $\mathrm{C}_{20} \mathrm{H}_{4} 0_{\mathrm{O}}$ & 0.17 \\
\hline 5 & 12.38 & Hexadecanoic acid, ethyl ester & $\mathrm{C}_{18} \mathrm{H}_{36} \mathrm{O}_{2}$ & 0.52 \\
\hline 6 & 12.60 & n-Hexadecanoic acid & $\mathrm{C}_{16} \mathrm{H}_{32} \mathrm{O}_{2}$ & 1.18 \\
\hline 7 & 14.32 & (E)-9-Octadecenoic acid ethyl ester & $\mathrm{C}_{20} \mathrm{H}_{38} \mathrm{O}_{2}$ & 0.09 \\
\hline
\end{tabular}


The compounds of the ethanol extract of Sargassum wightii were docked with the active amino acid residues of the COX2 protein, which was confirmed by the Glide, score (Maestro 9.4). The docking or in-Silico analysis was used to predict the binding orientation of the ligands to the protein targets in order to predict the affinity and activity of the small molecules.

The docking results of seven bioactive compounds from the ethanolic extract of Sargassum wightii were complexes with the COX2 protein are shown in Table.2. Out of the seven compounds five compounds namely methyl Salicylate, benzoic acid, 2-hydroxy- ethyl ester, diethyl phthalate, hexadecanoic acid, ethyl ester and (E)-9-Octadecenoic acid ethyl ester were showed better Glide score. The docking or Glide score of the above five compounds are: $-6.107,-6.398$, $6.255,-6.427,-8.080$ respectively and the glide energy were $-27.329,-29.615,-27.691,-33.193$ and $-33.952 \mathrm{kcal} / \mathrm{mol}$ respectively. The ligand compounds complexes with the COX2 protein are shown in Figure.3A-3E. The order of the highest negative glide score and the glide energy indicated that these complexes may have good affinity to COX2 [27]. The 2D ligand interactions with active amino acid site of COX2 are showed in Figure.4A-4E

The selected five compounds namely methyl salicylate, benzoic acid, 2-hydroxy- ethyl ester, diethyl phthalate, Hexadecanoic acid, ethyl ester and (E)-9-Octadecenoic acid ethyl ester were evaluated for their ADME properties using QikProp and the limitation of its properties [28] are: (a) not more than 5 hydrogen bond donors, (b) not more than 10 hydrogen bond acceptor, (c) the molecular weight less than 500 Daltons; (d) an octanol- water partition coefficient log P not greater than 5. The QikProp module results showed that the ADME properties of the selected five bioactive compounds were under acceptable range (Table.3).

Table.2. Docking results of COX2 protein with the 7 bioactive compounds from the GC-MS analysis of ethanolic extract of Sargassum wightii

\begin{tabular}{|c|l|c|c|}
\hline S.No & \multicolumn{1}{|c|}{ Compounds } & Glide score & Glide energy \\
\hline 1 & Methyl Salicylate & -6.107 & -27.329 \\
\hline 2 & Benzoic acid, 2-hydroxy-, ethyl ester & -6.398 & -29.615 \\
\hline 3 & Diethyl Phthalate & -6.255 & -27.691 \\
\hline 4 & Hexadecanoic acid, ethyl ester & -6.427 & -33.193 \\
\hline 5 & n-Hexadecanoic acid & -2.543 & -24.196 \\
\hline 6 & (E)-9-Octadecenoic acid ethyl ester & -8.080 & -33.952 \\
\hline
\end{tabular}

Table.3. ADME properties of selected five bio active compounds from the GC-MS analysis of ethanolic extract of Sargassum wightii

\begin{tabular}{|c|l|c|c|c|c|}
\hline S.No & \multicolumn{1}{|c|}{ Ligands } & $\begin{array}{c}\text { Molecular } \\
\text { weight } \\
\text { (g/mol) }\end{array}$ & $\begin{array}{c}\text { H-Bond } \\
\text { Donar }\end{array}$ & $\begin{array}{c}\text { H-Bond } \\
\text { Acceptor }\end{array}$ & $\begin{array}{c}\text { Log P } \\
\mathbf{O} / \mathbf{W}\end{array}$ \\
\hline 1 & Methyl Salicylate & 152.149 & 0 & 1.75 & 1.956 \\
\hline 2 & Benzoic acid, 2-hydroxy-, ethyl ester & 166.176 & 0 & 5 & -1.251 \\
\hline 3 & Diethyl Phthalate & 222.240 & 0 & 2 & 3.676 \\
\hline 4 & Hexadecanoic acid, ethyl ester & 284.481 & 0 & 4 & -0.310 \\
\hline 5 & (E)-9-Octadecenoic acid ethyl ester & 310.519 & 0 & 4 & -0.102 \\
\hline
\end{tabular}




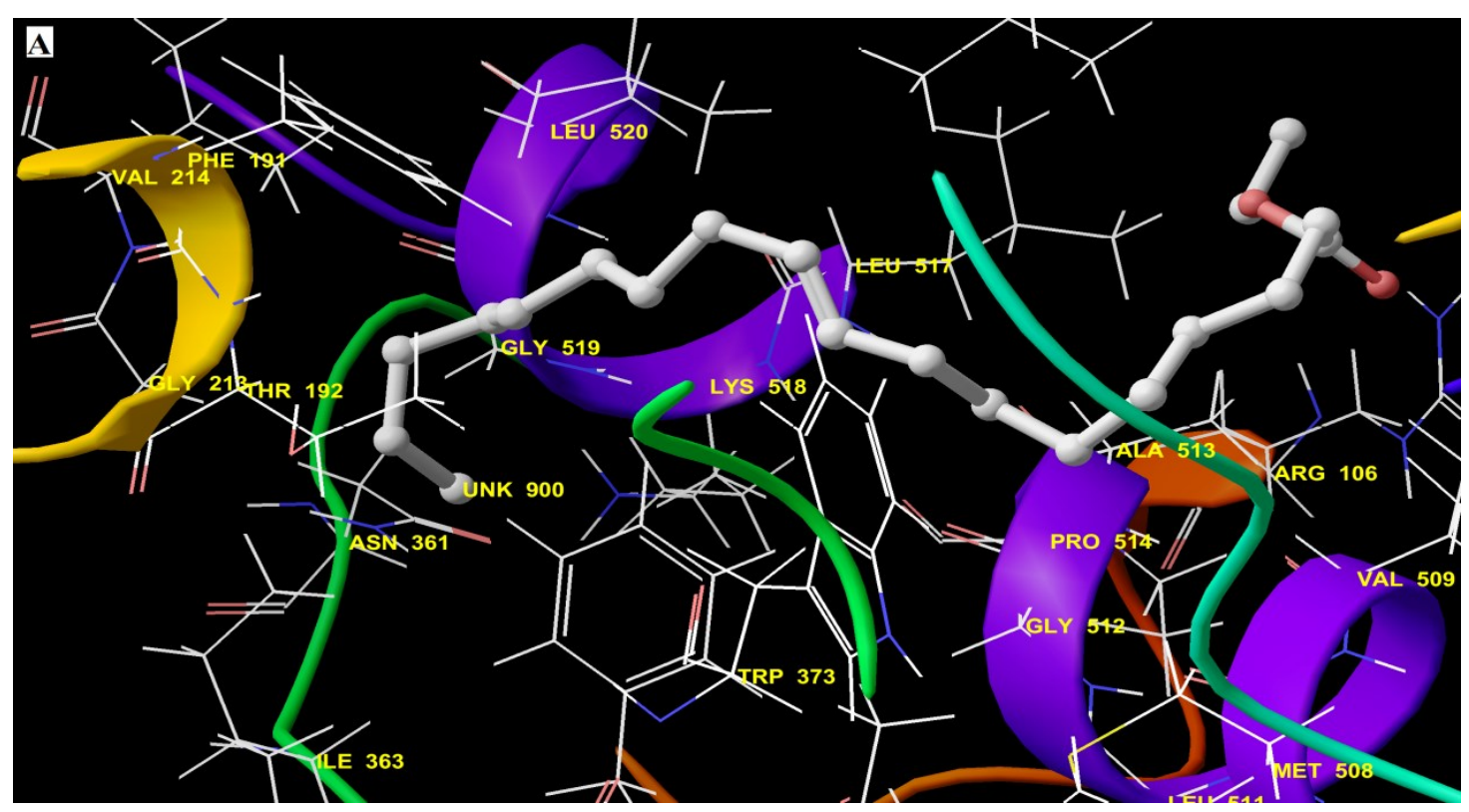

Figure.3A. Ligand (E)-9-Octadecenoic acid ethyl ester interaction with COX2 protein

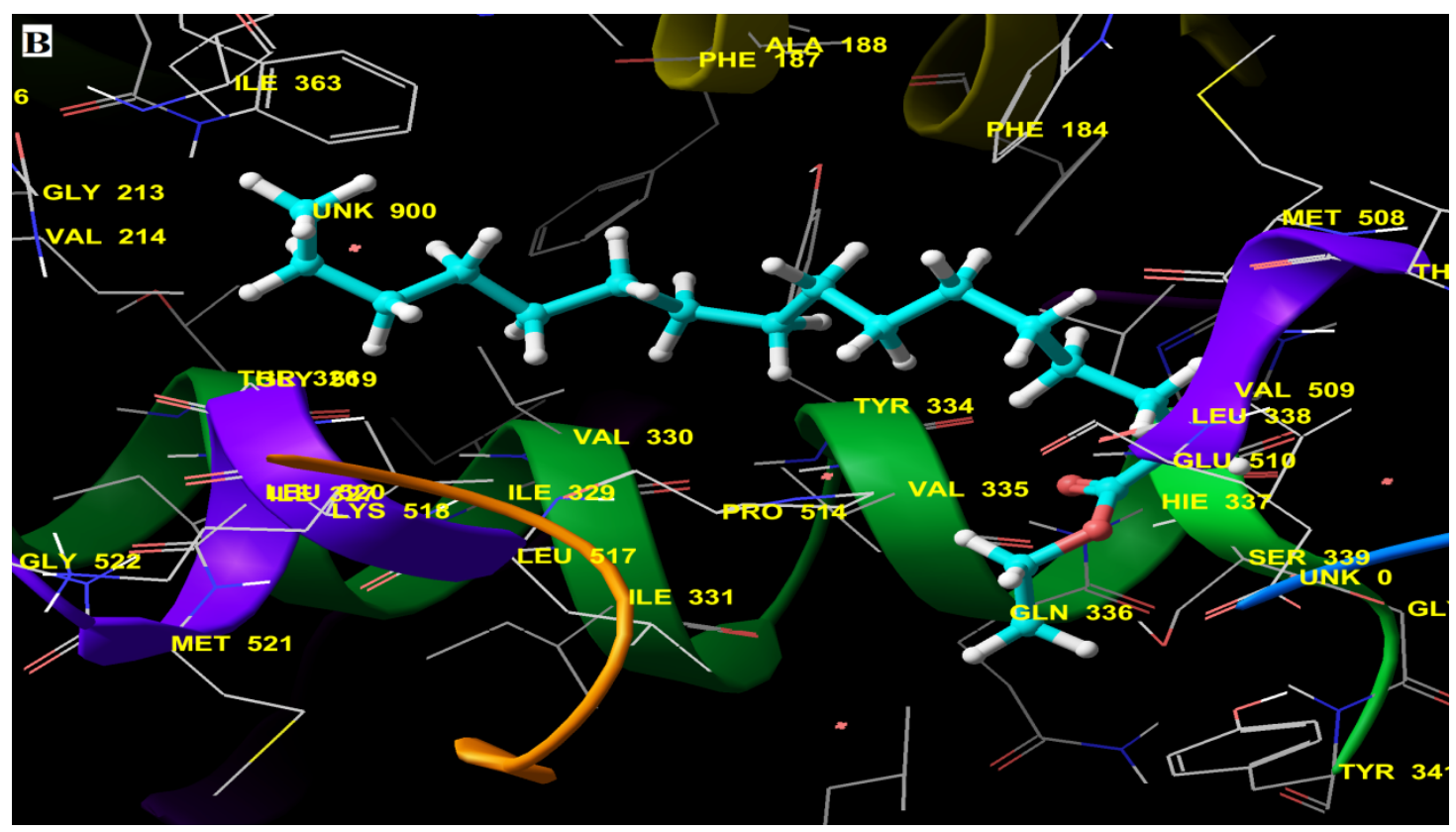

Figure.3B. Ligand - Hexadecanoic acid ethyl ester interaction with COX2 Protein 


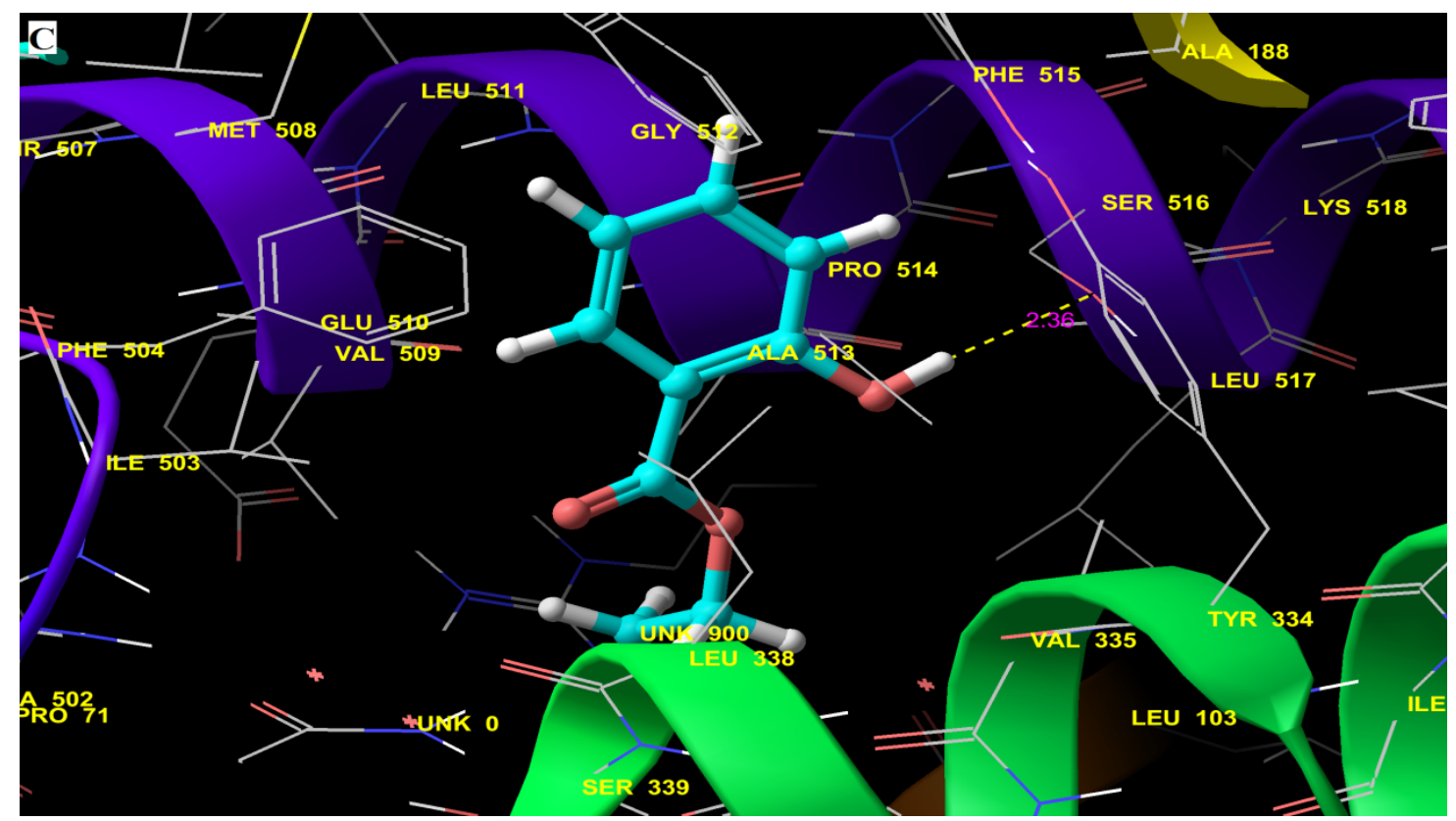

Figure.3C. Ligand - Benzoic acid 2-hydroxy-, ethyl ester interaction with COX2 protein

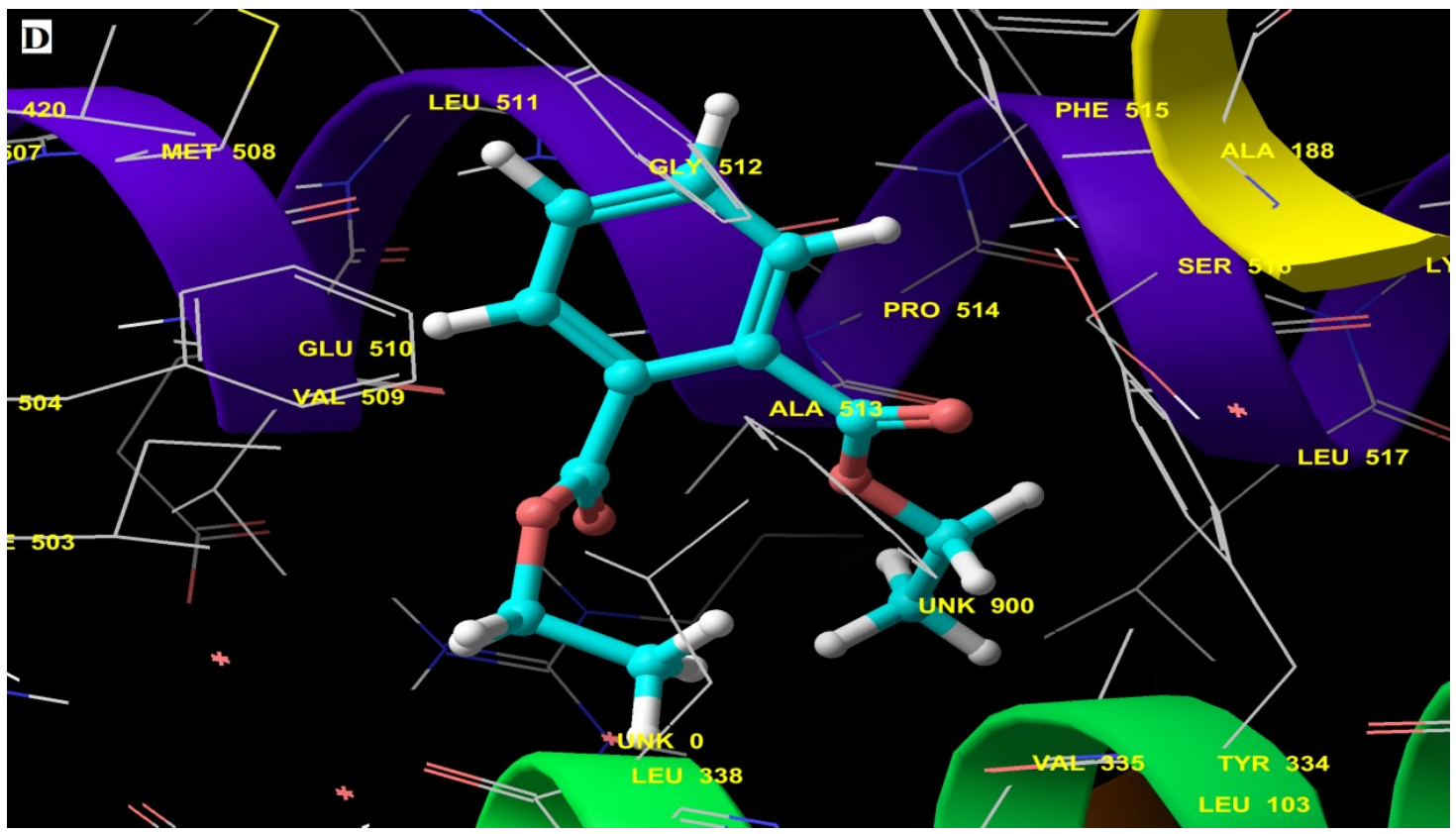

Figure.3D. Ligand - Diethyl Phthalate interaction with COX2 protein 


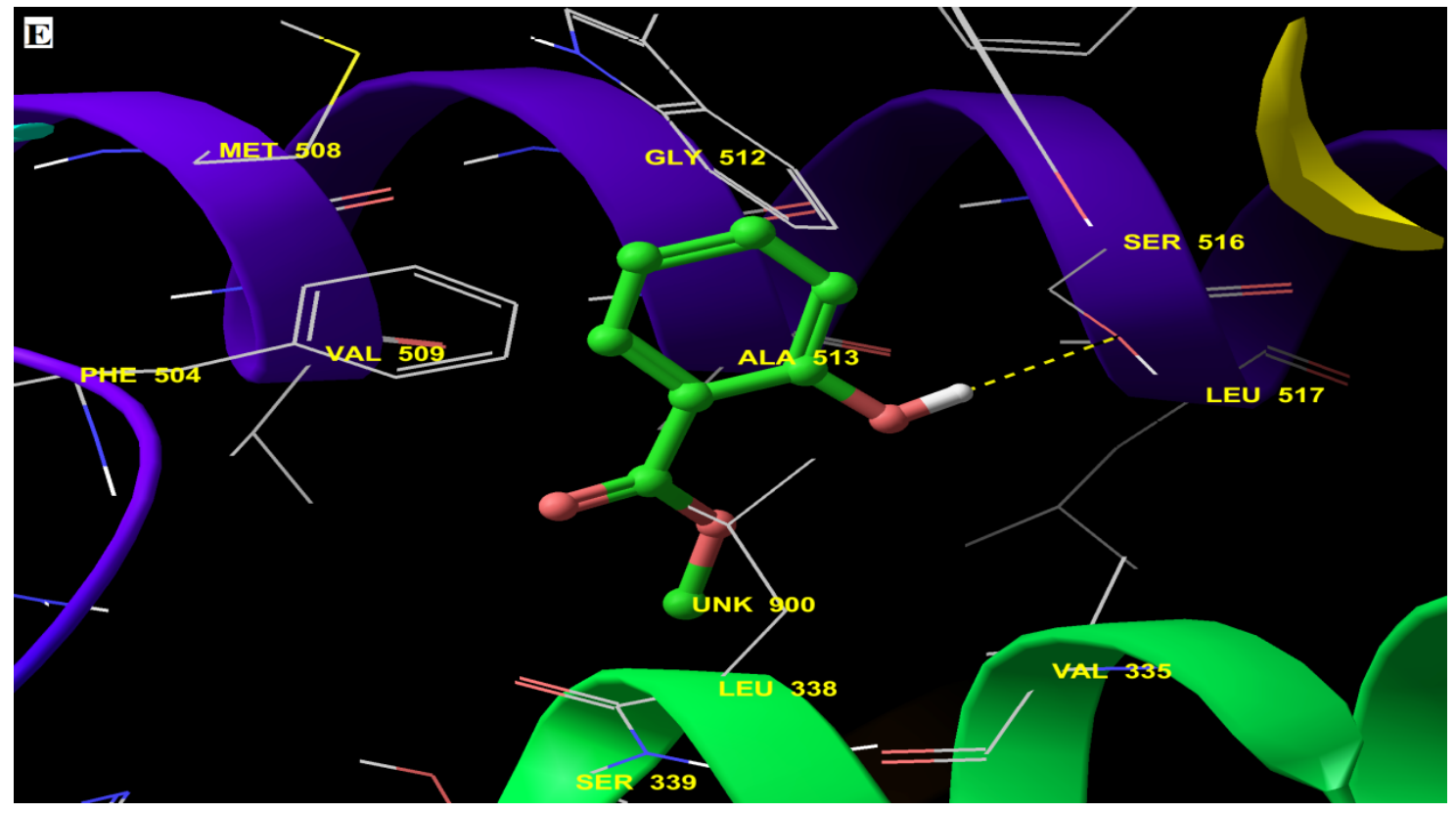

Figure.3E. Ligand - Methyl Salicylate interaction with COX2 protein

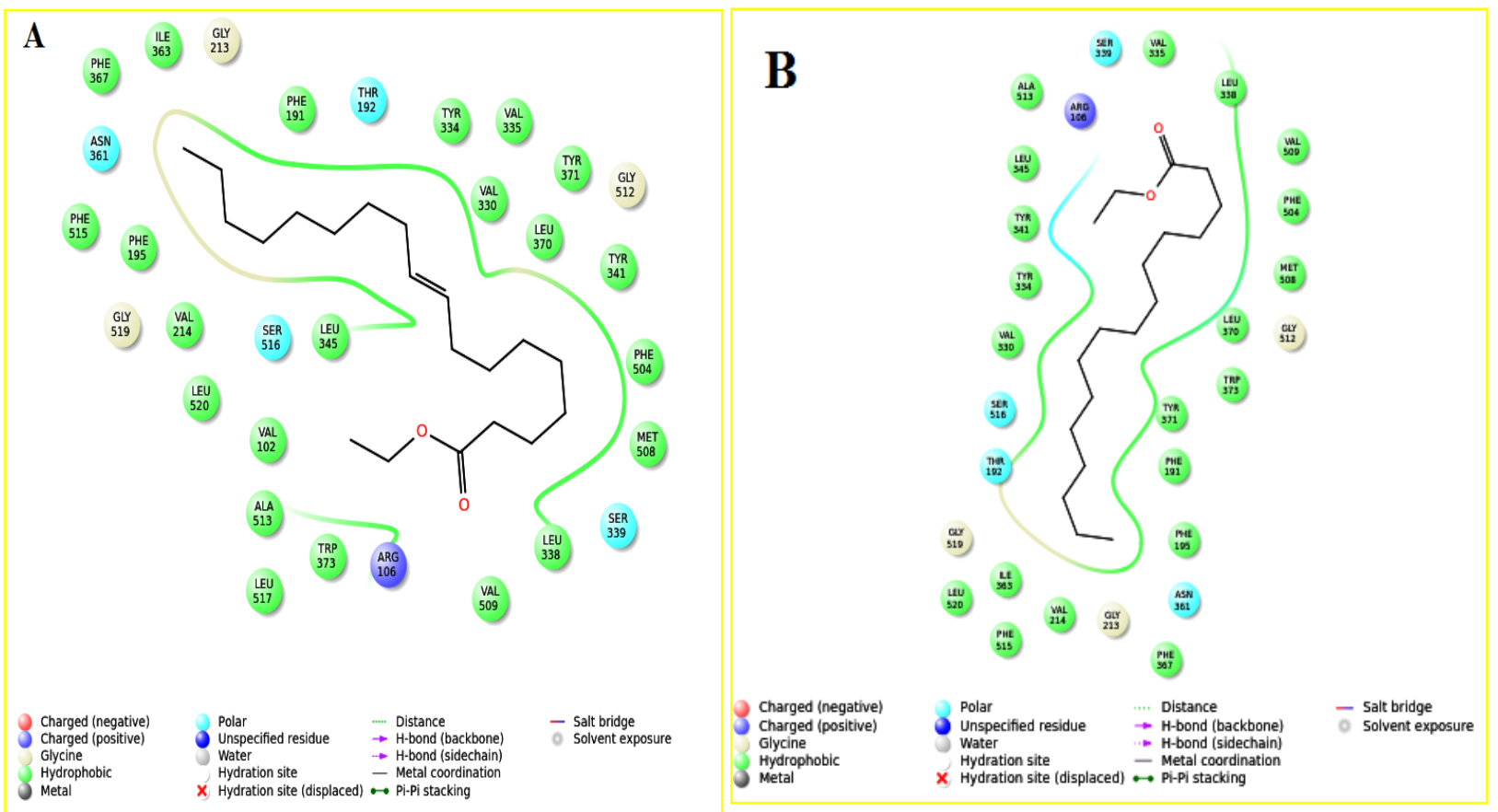




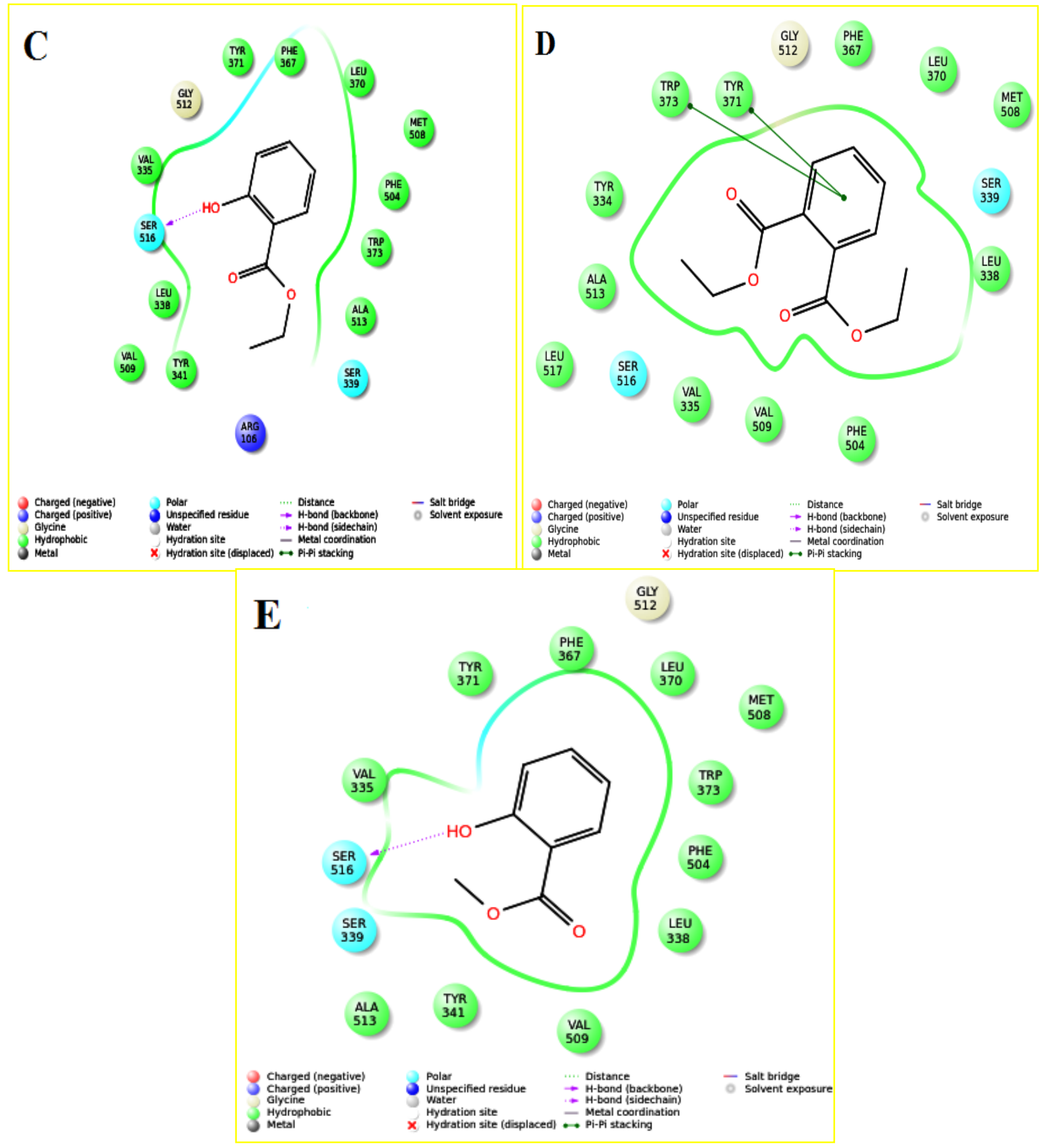

Figure.4. 2D interaction of the active site of COX2 with (E)-9-Octadecenoic acid ethyl ester (A); Hexadecanoic acid, ethyl ester (B); Benzoic acid, 2-hydroxy-, ethyl ester (C); Diethyl Phthalate (D); methyl Salicylate (E).

\section{CONCLUSION}

Seven bioactive compounds were identified from the ethanolic extract of Sargassum wightii using GC-MS analysis. The molecular docking studies showed that, out of these seven compounds, (E)-9-Octadecenoic acid ethyl ester, hexadecanoic acid, ethyl ester, benzoic acid, 2-hydroxy-, ethyl ester, diethyl phthalate, methyl salicylate showed better interaction with the active amino acid site of COX2 protein. The results of the study further confirmed a successful docking, intermolecular hydrogen bonding and lipophillic interactions with the ligand "COX2" receptor. From the docking results and the Glide score it was observed that five compounds possess good inhibitor activity 
against COX2. In addition to these the ADME properties of the five compounds were within the permitted limit. Interesting to note these ligands could be used to develop as a novel COX2 inhibitor for the treatment of inflammation, pain and stomach ulceration.

\section{References}

[1] S.K. Chaudhary., Quintessence of Medical Pharmacology, Experimental Therapeutics, Kolkata, 2001.

[2] C.W. Denko, J.T. Whicher, S.W. Evans, A role of neuropeptides in inflammation, Biochemistry of Inflammation, Kluwer Pub, London,1992.

[3] D.J. Watson, S.E. Harper, P.L. Zhao, H. Quan, J.A. Bolognese, T.J. Simon, Gastrointestinal tolerability of the selective cyclooxygenase-2 (COX2) inhibit orrofecoxib compared with nonselective COX1 and COX2 inhibitors in osteoarthritis, Arch Intern Med. 160 (2000) 2998-3003

[4] N. Neophytou, G. Leonis, N. Stavrinoudakis, M. Simcic, S.G. Grdadolnik, E. Papavassilopoulou, G. Michas, P. Moutevelis-Minakakis, M.G. Papadopoulos, M. Zing, T.mavromoustakos, Docking and Molecular Dynamics Calculations of Pyrrolidinone Analog MMK16 to COX and LOX Enzymes, Mol. Inf. 30 (2011) 2-15.

[5] May, M. Zacharias, Accounting for global protein deformability during protein-protein and protein-ligand docking, BBA Proteins Proteomics. 1754 (2005) 225-231.

[6] T. Chopin., M. Sawhney, Seaweeds and their Mariculture, Encyclopedia of Ocean Sciences, second ed., Oxford, Academic Press, USA, 317-326, 2008.

[7] A. Manilal, S. Sujith, G.S. Kiran, J. Selvin, C. Shikar, Cytotoxic potentials of red alga, laurenciabrandenii collected from the Indian Coast, Global J Pharmacol. 3 (2009) 90-94.

[8] J.E. Duffy, M.E. Hay, Seaweed adaptations to herbivory, American Institute of Biological Science. 40(5) (1990) 368-375.

[9] G.S El-Baroty, M.Y. Moussa, M.A. Shallan, M.A. Ali, A.Z. Sabh, E.A. Shalaby, Contribution to the Aroma, Biological Activities, Minerals, Protein, Pigments and Lipid Contents of the Red Alga: Asparagopsistaxiformis (Delile) Trevisan, J App Sci Res. 3 (2007) 1825-34.

[10] S. Mizukoshi, H. Matsuoka, H. Katou and H. Noda, Search for bioactive substances from marine algae, Bulletin Fac. Bioresource Mie Univ. MiediaSeibutsushigen Kiyo. 8 (1993) 2734.

[11] Boukhari \& Sophie, Anyone for algae? UNESCO Courier, 51(7/8) (1998) 31-32.

[12] A. Jiménez-Escrig \& F.J. Sánchez-Muniz, Dietary fibre from edible seaweeds, chemical structure, physicochemical properties and effects on cholesterol metabolism, Nutrition Research. 20 (2000) 585-598.

[13] C.H. Sarithakumari, G.L. Renju, G.M. Kurup, Anti-inflammatory and antioxidant potential of alginic acid isolated from the marine algae, Sargassum wightii on adjuvant-induced arthritic rats, Inflammopharmacology. 21 (2013) 261-268

[14] S. Kumaravel, P. Praveen Kumar, P. Vasuki, GC-MS Study on Microbial degradation of Lindane, International Journal of Applied Chemistry. 6(3) (2010) 363- 366.

[15] D.P. John, J. Pulapa, B.M. Naresh, C. Sashikanth, Virtual Screening and Molecular Docking Analysis of Zap-70 Kinase Inhibitors, International Journal of Chemical and Analytical Science. 2(9) (2011) 1208-1211. 
[16] Z. Li, H. Wan, Y. Shi, P. Ouyang, Personal experience with four kinds of chemical Structure Drawing Software, Review on ChemDraw, ChemWindow, ISIS/Draw, and Chemsketch, $J$. Chem. Inf. Comput. Sci. 44 (5) (2004) 1886-1890.

[17] T. A. Halgren, R. B. Murphy, R.A. Friesner, H.S. Beard, L.L Frye, W.T. Pollard, J.L. Banks, Glide: A New Approach for Rapid, Accurate Docking and Scoring. 2. Enrichment Factors in Database Screening, J. Med. Chem., 47 (2004) 1750-1759.

[18] M. Awale, X. Jin, J.L. Reymond, Stereo selective virtual screening of the ZINC database using atom pair 3D-fingerprints, J Cheminform. Feb 7 (3) (2015) 1-15.

[19] E. Bolton, Y. Wang, P.A. Thiessen, S.H. Bryant, PubChem: Integrated Platform of Small Molecules and Biological Activities, Chapter 12, Annual Reports in Computational Chemistry, Volume 4, Elsevier, Oxford, UK, 2008, pp. 217-240.

[20] Y. Wang, J. Xiao, T.O. Suzek, J. Zhang, J. Wang, S.H. Bryant, PubChem: a public information system for analyzing bioactivities of small molecules, Nucleic Acids Research, 37 (2009) W623-633.

[21] G. Madhavi Sastry, A. Matvey, D. Tay, A. Ramakrishna, S. Woody, Protein and Ligand preparation : parameters, protocols, and influence on virtual screening enrichments, Journal of Computer-Aided Molecular Design. 27(3) (2013) 221-234

[22] R.A. Friesner, R.B. Murphy, M.P. Repasky, L.L. Frye, J.R. Greenwood, T.A. Halgren, P.C. Sanschagrin, D.T. Mainz, Extra Precision Glide: Docking and Scoring Incorporating a Model of Hydrophobic Enclosure for Protein-Ligand Complexes, J. Med. Chem. 49 (2006) 61776196.

[23] H.M. Berman, The Protein Data Bank: a historical perspective, Acta Crystallographica Section A, Foundations of Crystallography. 64 (2008) 88-95.

[24] J.L. Wang, K. Aston, D. Limburg, C. Ludwig, A.E. Hallinan, F. Koszyk, B. Hamper, D. Brown, M. Graneto, J. Talley, T. Maziasz, J. Masferrer, J. Carter, The novel benzopyran class of selective cyclooxygenase-2 inhibitors. Part 2: the second clinical candidate having a shorter and favorable human half-life, Bioorg Med Chem Lett. 20(23) (2010) 7164-7168.

[25] W. Sherman, T. Day, M.P. Jacobson, R.A. Friesner R. Farid, Novel procedure for modeling ligand/receptor induced fit effects, J. Med. Chem, 49 (2006) 534-553.

[26] QikProp, version 3.6, Schrödinger, LLC, New York, New York, 2013.

[27] R.A. Friesner, J.L. Banks, R.B. Murphy, T.A. Halgren, J.J. Klicic, D.T. Mainz, M.P. Repasky, E.H. Knoll, M. Shelley, J.K. Perry, D.E. Shaw, P. Francis, P.S. Shenkin, Glide: A New Approach for Rapid, Accurate Docking and Scoring. 1. Method and Assessment of Docking Accuracy, J.Med.Chem, 47(7) (2004) 1739-1749.

[28] S.D. Walker, S.M. Eldowney, Molecular docking: A potential tool to aid ecotoxicity testing in environmental risk assessment of pharmaceuticals, Chemosphere. 93 (2013) 2568-2577. 